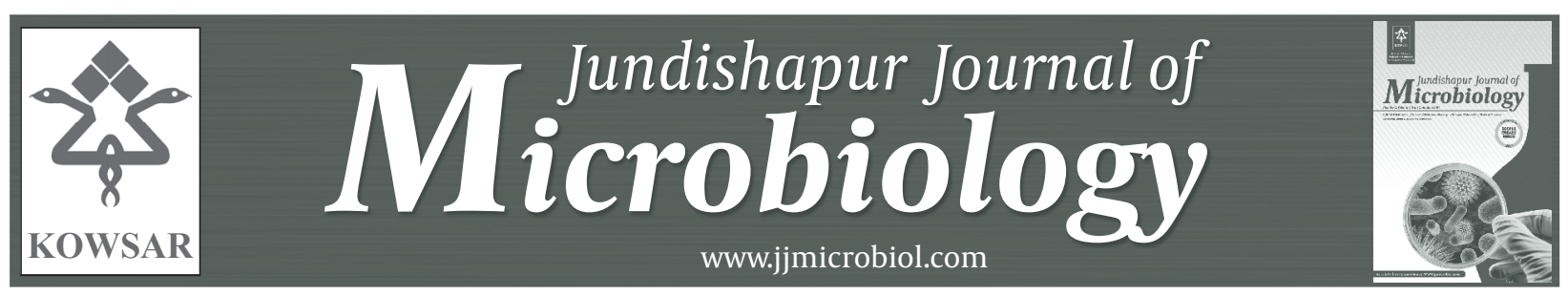

\title{
Comparison of Phenotypic Tests and PCR to Detect Candida albicans From Vaginal Specimens (Tabriz, 2009-2010)
}

\author{
Abdolhassan Kazemi ${ }^{1}$, Mehraban Falahati ${ }^{2^{*}}$, Ashraf Hajipoor ${ }^{1}$, Abbasali Jafari ${ }^{3}$, Moham- \\ mad Asghar zadeh ${ }^{4}$
}

${ }^{1}$ Tropical and Infectious Disease Research Center, Tabriz University of Medical Sciences, Tabriz, IR Iran

2 Department of Medical Parasitology and Mycology, Tehran University of Medical Sciences, Tehran, IR Iran

${ }^{3}$ Department of Medical Mycology, School of Medicine, Yazd University of Medical Sciences, Yazd, IR Iran

${ }^{4}$ Tropical and Infectious Disease Research Center, Tabriz University of Medical Sciences, Tabriz, IR Iran

* Corresponding author: Mehraban Falahati, , Parasitology and Mycology Department, School of Medicine, Tehran University of Medical Sciences, Tehran, IR Iran .Tel.: +98-2188058653, Fax: +98-2188058653, E-mail: flahatim@yahoo.co.in

\section{A B S T R A C T}

Background: Fungal vaginitis originates from yeasts that are active in the mucosa of the women's genital tract. The main yeast that causes fungal vaginitis is Candida albicans .

Objectives: The current study aimed to detect frequency of yeasts mainly C. albicans in vaginal specimens of women from Tabriz, Iran. For the above purpose, the sensitivity and specifity of traditional laboratory assays were compared with those of molecular method (PCR) by universal and species primers to detect C. albicans in vaginal samples.

Patients and Methods: In this study, 250 vaginal specimens were collected from women in Tabriz, East-Azerbaijan province, Iran during 20092010. Samples were examined to identify C. albicans by germ-tube test, chlamydoconidium formation test, preparation of wet smear using potassium hydroxide, and Polymerase Chain Reaction (PCR).

Results: 162 yeast species from 250 specimens were isolated in Sabroud Dextrose Agar (SDA) Medium. 106 (65.4\%) of them were germ tube formation positive, 86 (53\%) chlamydoconidium formation positive and 101(62.4\%) were PCR positive. Yeast cells and mycelia were detected in the isolates on direct microscopic examination. C. albicans accounted for $66.04 \%$ of cases and $34 \%$ were non-C. albicans species.

Conclusions: In conclusion, PCR may be the best method to detect Candida species.

Keywords: Candida Albicans; Polymerase Chain Reaction

Copyright (c) 2013, Kowsar Corp.; Published by Kowsar Corp.

Article type: Research Article; Received: 18 Mar 2012, Revised: 07 May 2012, Accepted: 22 May 2012; DOI: 10.5812/jjm.4734

Implication for health policy/practice/research/medical education:

Results of the current survey could be useful to detect Candida species in clinical samples by different laboratory techniques and to prevent obtaining false positive or false negative results during laboratory procedures.

Please cite this paper as:

Kazemi A, Falahati M, Hajipoor A, Jafari A, Asghar-zadeh M. Comparison of Phenotypic Tests and PCR to Detect Candida albicans From Vaginal Specimens (Tabriz, 2009-2010). Jundishapur J Microbiol. 2013;6(2):122-126. DOI: 10.5812/jjm.4734

Copyright (C) 2013 Ahvaz Jundishapur University of Medical Sciences; Published by Kowsar Corp.

This is an Open Access article distributed under the terms of the Creative Commons Attribution License (http://creativecommons.org/licenses/by/3.0), which permits unrestricted use, distribution, and reproduction in any medium, provided the original work is properly cited. 


\section{Background}

The valid and rapid laboratory assays to identify Candida species in clinical samples are particularly important to diagnose Candidal volvovaginitis of women. This clinical type of candidiasis can be very important and even significant among HIV+, pregnant, and immunodeficient women due to leading to systemic candidiasis in this group of patients. The currently used laboratory assays such as direct microscopy, culture, and biochemical methods to detect and identify Candida species accurately, are time-consuming, and lack the necessary validity. Also, the mentioned assays fail to discriminate between the pathogenic and virulent Candida species with non or less pathogenic species of Candida. This kind of laboratory findings and information are vital and critical to choose accurate therapeutic protocol, since some non-Candidal yeasts and also non-C. albicans species have been identified as fully antifungal resistant species or less susceptible to normally used antimycotic agents (1). Vulvovaginal candidiasis (VVC) originates from yeasts that are active in the mucosa of the women's genital tract. Recent reports have shown that the rate of VVC has elevated among women. C. albicans is the main yeast species that causes VVC (2) and accounts for around 70 to 90 $\%$ of clinical candidiasis, but other species such as: C. glabrata, C. krusei, C. tropicalis, C. parapsilosis, C. dubliniensis and rarely some other Candida Sp. play a 10 to $20 \%$ role in causative agents of VVC (3).

Around 20 to $25 \%$ of healthy asymptomatic women show vaginal specimens with active C. albicans (4). Moreover, three fourth of women have experienced VVC at least once, and half of them have experienced that many times, even recurrent status during their own life time.

\section{Objectives}

The current study aimed to detect frequency of yeasts mainly C. albicans in vaginal specimens of women from Tabriz, Iran. For the above purpose, the sensitivity and specifity of traditional laboratory assays were compared with those of molecular method (PCR) by universal and species primers to detect C. albicans in vaginal samples.

\section{Patients and Methods}

\subsection{Sample Collection and Culture}

From three health-care centers in Tabriz (governorship city in north-west of Iran) during 2009-2010 under supervision of gynecologists, a total number of 250 vaginal specimens were collected by a disposable vaginal sterile speculum and two sterile swabs from infected or suspected, asymptomatic or symptomatic women to candidiasis, irrespective of symptoms. Clinical samples were immediately transferred to medical mycology lab (Tabriz University of Medical Sciences) under sterile condition. The women were from different cites of East Azerbaijan province. All cases were informed, and they consented to participate in the study. One of the obtained swabs was spread on the sterile condition in culture medium Sabouraud Dextrose Agar (SDA) Petri dish (Oxiod Ltd., UK). The dishes were incubated at $37^{\circ} \mathrm{C}$, for $48-72$ hours. The next swab was used for smear preparation.

\subsection{Vaginal Smear}

The second swab was rubbed on a sterile microscopic slide used in wet smears preparation; this slide was treated with a drop of $10 \%$ potassium hydroxide ( $\mathrm{KOH})$. The smears were studied microscopically to identify yeast characteristics and hyphal (mycelium and pseudomycellium) structures of Candida.

\subsection{Germ Tube Test and Chlamydoconidium For- mation Test}

The germ tube-formation ( $R B$ phenomenon) test was performed, to detect $C$. albicans using $72 \mathrm{~h}$ cultures on Sabouraud Dextrose Agar + Chloramphenicol (SC) media. The yeast colony ( $\sim 106$ yeast cell) was incubated in $2000 \mu \mathrm{l} \mathrm{hu-}$ man fresh serum at $37^{\circ} \mathrm{C}$ for maximum 2 hours and then studied by microscope. One of the discriminating features of C. albicans is chlamydoconidium formation on Corn Meal Agar (CMA) medium with 1\% Tween 80. Samples were cultured in CMA containing $1 \%$ tween 80 , and then incubated in 27 to $30^{\circ} \mathrm{C}$ for three days. After incubation, plates were studied for typical chlamydoconidium formation. All used fungal media were from Oxiod Ltd., UK.

\subsection{DNA Extraction and Polymerase Chain Reac- tion (PCR)}

Genomic DNA of the C. albicans was extracted by DNA Extraction Kit (Qiagen, Germany) according to manufacturer instructions for Fungal DNA extraction. Primer (1):

Forward Primer: 5'- TCA ACT TGT CAC AGA TTA TT-3'

Reverse Primer: 5'- TCC TCC GCT TAT TGA TAT GC-3' The PCR cycle parameters were as follows: preheating at $94^{\circ} \mathrm{C}$ for 3 minutes, followed by 42 cycles of $94^{\circ} \mathrm{C}$ for $1 \mathrm{~min}$ (denaturing step), $50^{\circ} \mathrm{C}$ for 25 seconds (annealing step) and extention at $72^{\circ} \mathrm{C}$ for $25 \mathrm{sec}$, finally $72^{\circ} \mathrm{C}$ for $5 \mathrm{~min}$. (for total $50 \mu \mathrm{l}$ of PCR reaction the details of PCR mixture was: each primer: $1 \mu \mathrm{l}$, template DNA: $1 \mu \mathrm{l}$, Taq DNA polymerase: $0.5 \mu \mathrm{l}, 5 \mathrm{x}$ PCR buffer: $5 \mu \mathrm{l}$, ddH2O:31.5 $\mu \mathrm{L}$ ). All reaction mixtures were amplified by means of a thermal cycler (FPHC3CD Thermal Cycler, Techne, England). The PCR products were electrophoresed in a $1 \%$ agarose gel (Roche Diagnostics GmbH, Mannheim, Germany). The gel was dyed with ethidium bromide (Fermentas $0.5 \mu \mathrm{g} / \mathrm{mL}$ ) and visualized under UV illumination. 


\section{Results}

Out of 250 vaginal specimens, 162 (64.8\%) yeast isolates were separated in SDA Medium. Of the 162 isolates, 106 (65.4\%) were germ tube formation positive in human fresh serum and 86 (53\%), chlamydoconidium formation positive using CMA medium and 101 (62.4\%) were PCR positive (Figure 1). Other related results are indicated in Table 1 . Of the 250 specimen, 162 (64.8\%) were showing yeast cells and mycelia on direct microscopic examination. $C$. albicans accounted for $66.04 \%$ of cases and $34 \%$ were other Candida species.

Table 1.. The Results of Vaginal Specimens by Three Different Tests to detect $C$. albicans (Total of Specimens $=250$ )

\begin{tabular}{llll}
\hline & $\begin{array}{l}\text { PCR for } C . \\
\text { albicans, } \\
\text { No.(\%) }\end{array}$ & $\begin{array}{l}\text { Germ Tube } \\
\text { Formation, } \\
\text { No.(\%) }\end{array}$ & $\begin{array}{l}\text { Chlamydo- } \\
\text { conidium } \\
\text { Formation }\end{array}$ \\
\hline Positive & $101(62.3)$ & $106(65.4)$ & $86(53 \%)$ \\
Negative & $61(37.6)$ & $56(34.5)$ & $76(46.9 \%)$ \\
Total & $162(100)$ & $162(100)$ & $162(100 \%)$ \\
\hline
\end{tabular}

Figure 1. Detection of C. albicans by PCR

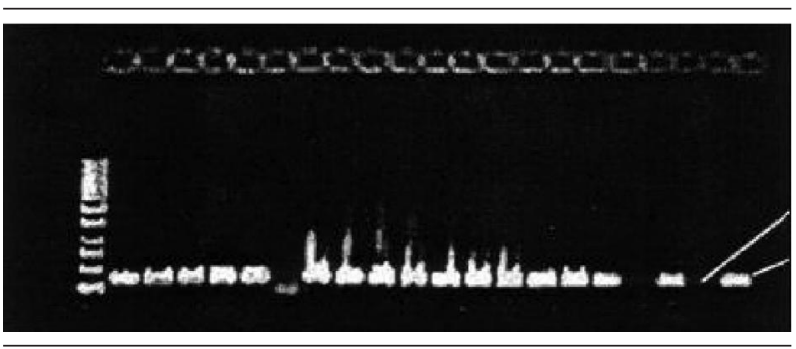

M: marker, Lanes 1 to 5: C. albicans (370 bp shows C. albicans bands) Lane 6: non-albicans Candida, Lane 17 and 19: Negative control, Lane 18 and 20: Positive control.

\section{Discussion}

The main purpose of this survey was to compare the validity and sensitivity of three common laboratory methods to detect $C$. albicans. Hence, attention to the clinical furthers of examined cases was not the scope of survey. "Vulvovaginal candidiasis includes the spectrum of patients both with and without symptoms who have positive cultures and who phenotypically may range from having a total absence of symptoms to the presence of florid, severe disease"(5). All types of immunodeficiency but particularly decreased cell-mediated immunity (CME) and also Candida dependent factors such as dimorphism of C. albicans (ability to transform between the yeast and the mycellial structure), are playing key roles to develop VVC and other types of invasive Candida infection in susceptible patients (6-8). It has been reported that higher risks of different types of candidiasis including VVC with non-albicans species (C. glabrata, C. dubliniensis) may re- peatedly occur in certain groups of patients due to inadequate treatment protocols or special groups of patients such as diabetic (61.3\%) or elderly (51.2\%) patients with VVC (9-12).

In the current study phenotypic assays established variable utility to recognize C. albicans from other Candidal species. The use of chlamydoconidium and germ tube production to identify C. albicans isolates produced highly valid results to distinguish Candida isolates in comparison with wet slide and culture assay. Alongside wet slide and culture assay, molecular screening was enormously helpful as a sensitive, rapid, highly valid and also inexpensive method to identify C. albicans from other Candida isolates $(13,14)$.

In the current study, the prevalence of yeast species in vaginal specimens of 250 women was $64.8 \%$ (162/250), and $66 \%$ of them were C. albicans. These rates are similar to the previous study by Bauters et al. Another study showed $60.7 \%$ prevalence for C. albicans (15). In a report by Ahmad and Khan in India, Out of 1050 women, 215 (20.47\%) were positive for Candida species. Of 215 women, 172 (80\%) had $\mathrm{pH}$ within the normal range and 167 (77.67\%) were showing yeast cells and mycelia on direct microscopic examination. C. albicans accounted for $46.9 \%$ of cases (16). While C. albicans is the most common species, increasing number of non-albicans isolates in vaginal candidiasis is obvious (17). In the current study, 34\% of isolates were non-albicans species. The rate of non-albicans infections is $>10 \%$ in specialized clinics and, occasionally, $>20 \%$ (5).

The germ tube test was found to have a sensivity and specificity of $84.6 \%$ and $100 \%$, respectively (18). Hoppe et al, estimated specificity and sensivity as $98 \%$ (19). Merlino et al., reported that all of C. albicans isolates were germ tube positive but two C. tropicalis gave false positive results (20). Although germ tube test is performed quickly, the use of risky sera and false positive results by $C$. tropicalis and $C$. dubliniensis are the major drawbacks of the test (21). Furthermore, it has been stated that $5 \%$ of C. albicans isolates do not produce germ tubes (22). The values of Youcesoy et al. were lower in comparison with those of other papers. They explained that use of human serum; different strains isolated from immunocompromised patients or from patients who had therapies by antifungal drugs might be the reason of these values. Candida species such as C. kefyr, C. guilliermondii and C. tropicalis were misinterpreted as positive by germ tube test (21). False-negative germ tube findings may occur in inappropriate conditions, such as heavy inoculums or error in busy laboratories (23). In the current investigation 5 out of 106 germ tube positive cases were false positive that is higher than both Merlino's and Youcesoy's study $(20,21)$.

Giraldo et al. reported that vaginal candidiasis could be detected in $28.8 \%$ of asymptomatic women by polymerase chain reaction technique and in $6.6 \%$ by culture (24). In the current survey, there were more women suspected to 
C. albicans caused by vaginal candidiasis, $40.4 \%$ (101/250) for PCR and 64.8 \% (162/250) for culture positive vaginal candidiasis.

Chlamydospores are thick-walled, refractile cells of unknown function. Staining with lactophenol cotton blue (LCB) facilitates differentiation of chlamydospores from hyphal and pseudohyphal cells (25). 53.09\% (86/162) of isolates positive for chlamydospore test and two cases of false positive results were detected in the current study, which may be due to the technician error or other near species (25) that produce chlamydospore .

Although the sensitivity of the 10\% potassium hydroxide examination is higher, at least one third of patients with symptomatic vulvovaginal candidiasis will have negative findings with potassium hydroxide microscopy (5). In the current study the $10 \%$ potassium hydroxide test was not positive in all of samples, around $50 \%(80 / 162)$ of samples were negative.

The basis for common techniques of fungal detection is isolation and culturing, identification by morphology and biochemical tests. Also, these techniques are laborious, prone to error, need skillful technicians and the ability of the fungus to be cultured (26). New, rapid screening methods are being developed and increasingly used in all aspects of fungal diagnostics. These methods include immunological methods, DNA/RNA probe technology and polymerase chain reactions (PCR) technology (26).

Mahens et al., used PCR to differentiate C. albicans and $C$. dubliniensis (27). PCR has the potential of detection in low amounts of DNA and helps the rapid diagnosis of pathogenic fungi that is critical in treatment of candidiasis. Also, PCR is more sensitive and specific than other traditional detection methods. PCR and molecular techniques may be the best choice for rapid and exact detection of $C$. albicans and other Candida species in vaginal specimens.

$162(64.8 \%)$ cases out of 250 clinical isolates from episodes of VVC in suspected patients were yeast according to their wet slides microscopic phenomena. At the same time 162 (64.8\%) samples were confirmed as Candida by a primary culture method followed by different detection assays including germ tube formation [106 (65.4\%)], chlamydoconidium formation [86 (53\%)], and molecular studies [and 101(62.4\%)] to establish identity.

In a comparison among PCR, germ tube, and chlamydoconidium test results, all three assays confirmed identity of 86 samples as C. albicans, but PCR did not confirm the identity of 5 and 15 samples as C. albicans in comparison with germ tube and chlamydoconidium tests respectively, as shown in Table 1 with some additional data.

\section{Acknowledgements}

The authors would like to express their gratitude to the department of medical parasitology and medical mycology of Tehran University of Medical Sciences for scientific assistance.

\section{Financial Disclosure}

There is no Financial Disclosure for this survey.

\section{Funding/Support}

This study was financially supported by Tehran University of Medical Sciences,Tehran, Iran.

\section{Authors' Contribution}

None declared.

\section{References}

1. Ahmad S, Khan Z, Mustafa AS, Khan ZU. Seminested PCR for diagnosis of candidemia: comparison with culture, antigen detection, and biochemical methods for species identification. J Clin Microbiol. 2002;40(7):2483-9.

2. Odds FC, Webster CE, Riley VC, Fisk PG. Epidemiology of vaginal Candida infection: significance of numbers of vaginal yeasts and their biotypes. Eur J Obstet Gynecol Reprod Biol.1987;25(1):53-66.

3. Sobel JD. Candida vulvovaginitis Semin Dermatol. 1996;15(1):17-28.

4. Consolaro MEL, Albertoni TA, Yoshida CS, Mazucheli J, Peralta RM, Svidzinski TIE. Correlation of Candida species and symptoms among patients with vulvovaginal candidiasis in Maringá, Paraná. Brazil Rev Iberoam Micol. 2004;21(4):202-5.

5. Sobel JD, Faro S, Force RW, Foxman B, Ledger WJ, Nyirjesy PR, et al. Vulvovaginal candidiasis: epidemiologic, diagnostic, and therapeutic considerations. Am J Obstet Gynecol. 1998;178(2):203-11.

6. Bader MS, Lai SM, Kumar V, Hinthorn D. Candidemia in patients with diabetes mellitus: epidemiology and predictors of mortality. Scand J Infect Dis. 2004;36(11-12):860-4.

7. Lo HJ, Kohler JR, DiDomenico B, Loebenberg D, Cacciapuoti A, Fink GR. Nonfilamentous C. albicans mutants are avirulent. Cell. 1997;90(5):939-49.

8. Romani L, Mencacci A, Grohmann U, Mocci S, Mosci P, Puccetti P. Neutralizing antibody to interleukin 4 induces systemic protection and $\mathrm{T}$ helper type 1-associated immunity in murine candidiasis. J Exp Med.1992;176(1):19-25.

9. Dan M, Segal R, Marder V, Leibovitz A. Candida colonization of the vagina in elderly residents of a long-term-care hospital. Eur J Clin Microbiol Infect Dis. 2006;25(6):394-6.

10. Goswami D, Goswami R, Banerjee U, Dadhwal V, Miglani S, Lattif AA, et al. Pattern of Candida species isolated from patients with diabetes mellitus and vulvovaginal candidiasis and their response to single dose oral fluconazole therapy.J Infect. 2006;52(2):111-7.

11. Kirkpatrick WR, Revankar SG, McAtee RK, Lopez-Ribot JL, Fothergill AW, McCarthy DI. Detection of Candida dubliniensis in oropharyngeal samples from human immunodeficiency virusinfected patients in North America by primary CHROMagar Candida screening and susceptibility testing of isolates. J Clin Microbiol. 1998;36(10):3007-12.

12. Ray D, Goswami R, Banerjee U, Dadhwal V, Goswami D, Mandal $\mathrm{P}$, et al. Prevalence of Candida glabrata and its response to boric acid vaginal suppositories in comparison with oral fluconazole in patients with diabetes and vulvovaginal candidiasis. Diabetes Care. 2007;30(2):312-7.

13. Sweet CE, Kaufman L. Application of agglutinins for the rapid and accurate identification of medically important Candida species. Appl Microbiol.1970;19(5):830-6.

14. Trama JP, Adelson ME, Raphaelli I, Stemmer SM, Mordechai E. Detection of Candida species in vaginal samples in a clinical laboratory setting. Infect Dis Obstet Gynecol. 2005;13(2):63-7.

15. Abu-Elteen KH, Abdul Malek AM, Abdul Wahid NA. Prevalence and susceptibility of vaginal yeast isolates in Jordan. Mycoses. 1997;40(5-6):179-85.

16. Ahmad A, Khan AU. Prevalence of Candida species and potential risk factors for vulvovaginal candidiasis in Aligarh, India. Eur J 
Obstet Gynecol Reprod Biol. 2009;144(1):68-71.

17. Spinillo A, Capuzzo E, Gulminetti R, Marone P, Colonna L, Piazzi G. Prevalence of and risk factors for fungal vaginitis caused by non-albicans species. Am J Obstet Gynecol. 1997;176(1 Pt 1):138-41.

18. Ainscough S, Kibbler CC. An evaluation of the cost-effectiveness of using CHROMagar for yeast identification in a routine microbiology laboratory. J Med Microbiol. 1998;47(7):623-8.

19. Hoppe JE, Frey P. Evaluation of six commercial tests and the germ-tube test for presumptive identification of Candida albicans. Eur J Clin Microbiol Infect Dis. 1999;18(3):188-91.

20. Merlino J, Tambosis E, Veal D. Chromogenic tube test for presumptive identification or confirmation of isolates as Candida albicans. J Clin Microbiol. 1998;36(4):1157-9.

21. Yucesoy M, Esen N, Yulug N. Use of chromogenic tube and methyl blue-sabouraud agar for the identification of Candida albicans strains. Kobe J Med Sci. 2001;47(4):161-7.

22. Quindos G, San Millan R, Robert R, Bernard C, Ponton J. Evalua- tion of bichro-latex albicans, a new method for rapid identification of Candida albicans. J Clin Microbiol. 1997;35(5):1263-5.

23. Foongladda S, Haouharn P, Sakulmaiwatana P, Chaiprasert A. Comparative evaluation of Candi Select test and conventional methods for identification of Candida albicans in routine clinical isolates. Mycoses. 2002;45(3-4):75-8.

24. Giraldo P, von Nowaskonski A, Gomes FA, Linhares I, Neves NA, Witkin SS. Vaginal colonization by Candida in asymptomatic women with and without a history of recurrent vulvovaginal candidiasis. Obstet Gynecol. 2000;95(3):413-6.

25. Coleman DC, Sullivan DJ, Bennett DE, Moran GP, Barry HJ, Shanley DB. Candidiasis: the emergence of a novel species, Candida dubliniensis. AIDS. 1997;11(5):557-67.

26. Atkins SD, Clark IM. Fungal molecular diagnostics: a mini review. J Appl Genet. 2004;45(1):3-15.

27. Mahnss B, Stehr F, Schafer W, Neuber K. Comparison of standard phenotypic assays with a PCR method to discriminate Candida albicans and C dubliniensis. Mycoses. 2005;48(1):55-61. 